\title{
Investigating the Impact of Dissuasive Factors of the Fuel and Oil Products Smuggling in the Customs of Iran
}

\author{
Reza Ghorbani* Mohammad Reza Alvandi \\ Iran of Republic Islamic the of Customs ,Mahirood Customs ,South Khorasan ,Birjand ,Iran
}

\begin{abstract}
The huge difference in the price of Iran's fuel across borders due to national subsidies to oil products and the fuel crisis in neighboring countries has caused smuggling of heavy goods to account for the highest rates of trafficking in goods from inside the country. Increasing fuel trafficking from the borders of the country is due to the huge difference in fuel prices in Iran with neighboring countries. In addition to the severe blows that the smuggling of these drugs causes on the economy of the region and the country, it leads to a false crisis and its dangers. Different perceptions of existing laws are different and various from the laws on similar issues, including the problems faced by the judiciary and government departments in counteracting the violations of fuel products. This study, considering the shortcomings and shortcomings of the smuggling of gas in the Iranian customs as well as the manner in which services are provided by customs, is to investigate the deterrent factors of smuggling fuel and oil products. For this purpose, a research was carried out at the customs level of the Mahirood border zone.
\end{abstract}

Keywords: Smuggling, Iran Customs, Border Areas, Oil Products, Customs Rules.

DOI: $10.7176 /$ RHSS/9-12-08

Publication date: June $30^{\text {th }} 2019$

\section{Introduction}

Smuggling means abduction and secret behavior as well as elusive and in the sense of customs as fraud in the transportation of goods without payment of customs duties and commercial profits. Obviously, any goods entering the country and their transactions illegally from the state it is prohibited to smuggle. Smugglers are often considered to be importing, exporting and transporting goods illegally without government permission and customs clearance. In this regard, all acts and activisms are completely secretly and illegally organized and do not pay attention to the law enforcement agencies secretly and do not pay the government's rights Redeem.

In legal terms, smuggling means transporting goods from place to place from one point to a few points abroad or inside the country. Obviously, these measures violate the law, however, smuggling has several types, most notably is as follows:

- Smuggling of currency, customs and commercial goods, and especially types of strategic goods, such as petroleum products

- Smuggling of weapons and ammunition and firefighting equipment, especially of a small type

- Trafficking in national works and antiquities

- Drug trafficking, tobacco, especially the new generation of psychedelic

- Trafficking in human beings and kidnapping

In general, smuggling is described as hidden, black, secret, intrusive, gray and brute, informal, invisible, irregular, illegal, parallel, secondary, shadow, latent, underground, intangible, intangible, unregistered and unregistered. Also called.

Smuggling has four types of losses for the country: 1. Losses for the people. 2. Losses for guilds. 3. Losses for manufacturers. 4. Losses for the government.

Smuggling is a fatal and destructive phenomenon that has inflicted great damage on the national economy and has undermined the activities of the official economy and our country's programs and policies. Therefore, unfortunately, problems such as declining domestic production and rising unemployment and the decrease in productive investment, and the reduction of entrepreneurship as well as the reduction of general government revenues. Nevertheless, various economic and non-economic factors have contributed to the phenomenon of smuggling commodities and currencies, due to the need for a careful study to contain this dangerous phenomenon as a scientific requirement seems necessary.

The smuggling of goods and especially petroleum products after the targeting of subsidies is unfortunately continuing to continue in this project, which has tried to provide appropriate and efficient solutions to combat this malicious phenomenon.

Today, smuggling is not unique to a particular commodity, and includes a very wide range of human trafficking, narcotics, petroleum products, weapons and alcoholic beverages and cigarettes, and so on, are one of the hallmarks of the deadly smugglers of the national economy, with very severe damage.

Since traffickers always act in the calculation of the profits and costs and the risks of smuggling beyond expectations, smugglers will be less inclined to smoke with increasing smuggling risk. Therefore, it is imperative for the government to thrive in order to curb the necessary measures so that the problem of unemployment and the 
growth of the working people and the national economy will flourish.

Smuggling of goods with disabilities is a variety of factors requiring national determination and careful attention to scientific indicators. Previous experience has shown that the fight against smuggling of goods has not been commensurate with the judiciary and, given cultural and preventive measures and job creation, will play an effective role in reducing smuggling. Obviously, the formulation of laws and the protection of domestic trade and production and attention to values Human and moral will ensure public security, especially in the border areas.

Considering the importance of energy and the need of neighboring countries, in particular, Afghanistan, Pakistan and Turkey, are the most important strategic goods for smuggling oil products abroad. Therefore, considering that Iran has an important place in terms of oil and gas reserves in the world, therefore, regardless of the price of extraction and processing of traffickers, they smuggle subsidized petroleum products to neighboring countries at present. Most of the oil smuggling is now smuggled to the land and offshore and gasoline frontiers of the country. Compared to the investigations, smuggling of oil products, especially gas oil through heavy vehicles, such as buses, minivans, trailers and trucks, oil carriers in the transportation sector, as well as tractors, combines, and reapers, and even through greenhouses and wells in the agricultural sector of the country. For gasoline engines also, cars such as rides and vans, as well as oil tanks, will do this.

Liquid gas smuggling is also a widespread occurrence of at least Afghanistan and Pakistan. Regardless of the smuggling of foodstuffs, imported goods from the country are also exported from the country for that currency, and goods such as textiles, rice, household appliances, tea, toys, clothing, through the borders of Sistan and Baluchistan, Iraq, especially the Zabul city Unfortunately, factors such as the low risk of smuggling the complexities of import and export regulations, the rising unemployment rate, the high interest in luxury, the price difference in Afghanistan and Iraq and Iran, the failure of some government agencies to perform their duties, are low. The level of living in a neighboring country and the presence of Afghans with a fake identity card in Cache the smuggling of oil products sharply increases in the east of the country. In spite of the implementation of subsidies targeting, the growing trend of smuggling, although moderated, continues to continue, which requires cultural planning and strict monitoring of the work of the machine Agricultural machinery, as well as the performance of supply pipelines and the optimal way of supplying fuel and distribution of petroleum gas in the easy trading system will also be monitored. (Ansari, 1373)

In general, in this research, we are trying to investigate what factors inhibit the smuggling of fuel at the Iranian borders (the case study of Mahirood boarder)?

Hopefully, by identifying these factors, we cannot use its results to reduce the smuggling of gas in Iran's customs.

\section{Research method}

The research is done in two ways. First, there are solutions to problems that are currently present in the workplace, which are called applied research, and the second is to add to a set of human knowledge in a particular field of interest to the researcher. The purpose of the fundamental research is to generate more knowledge and Understanding the phenomena that occurs and eventually presenting the theories based on the results of the research. Therefore, according to the above definitions, this research is called the applied research purpose. (Sekaran Uma, 8: 1381). According to the subject and hypotheses, the present research is applied in terms of purpose and descriptive and survey method. The information is gathered in field and non-field. In this research, the researcher has used the method to collect the required information and complete the questionnaires. In this research, the researcher studies the effect of deterrent factors on fuel and oil smuggling in Iran's customs (Case Study of Birjand Mahirood boarder Customs).

\section{3-3. Statistical Society}

Scientific research is conducted to identify a phenomenon in a statistical society. For this reason, the subject matter of the research may address the traits and characteristics, functions, and variables, or can study the relationships between variables, attributes, actions, and factors affecting the community. Therefore, the statistical society consists of all elements and individuals who have one or more common attributes on a given geographic scale.

Therefore, the more clear the image of the statistical community can be, the more accurate the sample can be selected and as a result of access to realistic information, therefore, in the present study, considering the temporal and spatial nature of the research, first, The exact population is analyzed and then the method and method of supplying the statistical sample is followed.

In the present study, considering the temporal and spatial domains of the research, the exact population of the statistical society is firstly determined and then the method and method of supplying the statistical sample is followed. The statistical population of this research consists of all employees working in the Birjand and Mahirood Customs office, which has been at least 3 years since the date of their work at Birjand and Mahirood Customs office. 


\section{3-4. Sample size and sampling method}

The statistical sample is a small sample of the statistical population that expresses the main qualities of society and the researcher is able to generalize the result to the whole society by studying it.

For the present study, according to the characteristics of the statistical society, a simple random sampling method without placement was chosen, and each employee employed at the Birjand customs office and the fishery that has been at least 3 years old since their date of work at Birjand customs and the river has passed, a sample unit was considered.

\section{3-5- Determining sample size}

In all studies, determining the appropriate sample size is very important, if the sample is too large, it will waste time and resources. While small samples will lead to inaccurate results. Therefore, selecting the appropriate sample size for each research depends on the acceptable or acceptable error rate. When sample data is collected and results such as the average of a particular parameter are calculated, this sample estimate will be significantly different from the average of the community, with a maximum difference of $5 \%$ in the research. As the sampling error decreases, the sample size will increase. And, as a result, it requires more time and money. To determine the sample size, also Jersey Morgan and Krejcie (Khal tbary, 2006: 129) was used. Based on the Morgan table formula, the sample size among the statistical population is as follows.

Morgan's $n=\frac{N \cdot t^{2} \cdot p(1-p)}{N \cdot d^{2}+t^{2} \cdot p(1-p)}$ formula:

$\mathrm{n}=$ sample size

$\mathrm{N}=$ total number of statistical population

$\mathrm{t}^{2}=\mathrm{t}$ student's value when the level is less than 0.05 .

$\mathrm{d}^{2}=$ approximation in the population parameter estimation, which is $0.05^{2}$

$\mathrm{P}=$ probability of being adjectives

$(1-\mathrm{P})=$ probability of failure

Considering the size of the statistical society, the placement of the above formula in the sample will be:

Morgan's formula: $n=\frac{20000 \times 1.64^{2} \times 0.5(1-0.5)}{20000 \times 0.05^{2}+1.64^{2} \times 0.5(1-0.5)}=100$

Therefore, we can continue to work by selecting at least 100 people from the statistical community. Therefore, a simple random sampling method will be used. A total of 130 questionnaires were distributed among the questionnaires. Subsequently, 100 completed questionnaires were selected as the final sample after a lot of followup and removal of incomplete questionnaires and those that were guessed.

\section{3-6. Data Collection Method}

In this research, different methods are used for data collection. Some of these methods are:

Library method: For collecting information about the history of research and literature, from specialized books and articles, dissertations and Internet databases have been used.

You know: Field data is used to collect the required data. In this way, the questionnaire was randomly distributed among the employees of the fishery's customs staff and then collected data and prepared for analysis.

\section{6- Measurement tool}

After several studies and interviews with individuals and experts, a researcher-made questionnaire was used for the research. The questionnaire, which was prepared using the Delphi method, in the first stage, determined 30 questions for the indicators. After 2 stages of editing, deleting unnecessary and repetitive questions, a questionnaire of 24 questions was provided with 6 indicators. Items related to each question based on the Likert scale 5 are scored as follows

Table 3-1: Code-setting of questions based on Optional Scale

\begin{tabular}{|c|c|c|c|c|}
\hline Very low & Low & Medium & Much & Very much \\
\hline 5 & 4 & 3 & 2 & 1 \\
\hline
\end{tabular}

Questions related to each chapter are described in the following table. 
Table 3-2: The headline of each question in the research questionnaire

\begin{tabular}{|c|l|c|}
\hline Number of related question & Headlines of questions & Row \\
\hline \hline 1 to 4 & Training of Customs Officers & 1 \\
\hline 5 to 8 & Getting heavy penalties from smugglers & 2 \\
\hline 9 to 12 & Compliance with government and customs regulations & 3 \\
\hline 13 to 16 & Use of modern equipment and facilities & 4 \\
\hline 17 to 20 & Rising fuel prices in the border regions & 5 \\
\hline 21 to 24 & Fuel retail in the border market & 6 \\
\hline
\end{tabular}

The main components of these questionnaires are:

A) A commentary letter: the purpose of collecting the data is by means of a questionnaire and the need for the respondent to cooperate and assuring them of the confidentiality of the information provided.

B) Instructions: At the beginning of each questionnaire, the answer to the questions is stated.

C) Questions of Questionnaires: All questions of the questionnaires are packaged and have several options to select from among respondents. The responses are such that the responder chooses and answers the answer with ease and speed, and, on the other hand, the data extraction can be done easily. In addition, the sample form of the questionnaire is in Annex 1.

\section{3-7. Validity and credit of measurement tools Validity of the questionnaire}

The concept of validity or validity answers the question to which extent the measurement tool measures the desired feature. Without being aware of the validity of the measuring instrument, it is not possible to carefully rely on the data obtained from it. Measurement tools may be valid for measuring a feature, while they do not have any credibility to measure the same characteristics in another society. The purpose of the validity is to measure the scale and the content of the tool or the questions contained in the instrument exactly the variables and the subject under study. Validity or credit of the questionnaire of this research is from the viewpoint of experts and experts (content validity and use of standard questionnaires for designing questionnaires questionnaires).

Reliability (internal validity)

The reliability or reliability of the measurement tool, which is also interpreted as credibility, accuracy, and reliability, is that the measurement tool made for measuring variables and attributes. If similar conditions are used at another time or place, similar results can be obtained. In other words, a valid or reliable tool is a tool that has the same property of repeatability and measurement of results. One of the methods for calculating reliability is the use of Cronbach's alpha method. This method is used to compute the internal coordination of the measurement tool, such as questionnaires or tests that measure different characteristics. In this tool, the answer to each question can be set to different numerical values. To calculate the Cronbach's alpha coefficient, firstly, the variance of each subset of the questionnaire with sub-test and total variance was obtained. Then, using the following formula, the amount of alpha coefficient was calculated.

$r a=\frac{j}{j-1}\left(1-\frac{\sum S^{2} j}{S^{2}}\right)$

$\mathrm{J}$ : Number of sub questionnaire or test questions

\section{$S^{2} j$ : Variance of the following $\mathrm{j} \quad S^{2}$ : Variance of the whole test}

Since Cronbach's alpha is usually a good indicator for measuring the reliability of the instrument of measurement and the internal coordination among its elements. Therefore, the reliability of the questionnaire used in this study was evaluated using Cronbach's alpha.

Table 3-3: Cronbach's alpha coefficients for the research variables in the final sample

\begin{tabular}{|l|l|l|}
\hline Alpha coefficients & Headlines of questions & Row \\
\hline \hline 0.7649 & Training of Customs Officers & $\mathbf{1}$ \\
\hline 0.7513 & Getting heavy penalties from smugglers & 2 \\
\hline 0.8012 & Compliance with government and customs regulations & 3 \\
\hline 0.8222 & Use of modern equipment and facilities & 4 \\
\hline 0.8170 & Rising fuel prices in the border regions & 5 \\
\hline 0.8263 & Fuel retail in the border market & 6 \\
\hline 0.9580 & Total factors & - \\
\hline
\end{tabular}

Given the suitability of the alpha coefficients, the internal validity is confirmed.

\section{3-8.Data analysis methods}

In this research, descriptive and inferential statistics were used to analyze the data. In descriptive statistics, 
frequency tables, percentages, mean and standard deviations, and inferential statistics, Kolmogrov-Smirnov test is used to determine the normality of the variables and to test a sample sign and Friedman to answer the assumptions of the research. Meanwhile, Spss version 16 was used to perform calculations.

\section{Results and discussion}

Assumption of the normalization of variables test

Before determining the type of test used, especially in the comparative tests, it is necessary to make sure that the variables are normal.

Table 4-5: Kolmogorov Smirnov test for research variables

\begin{tabular}{|c|c|c|c|c|}
\hline Result & $\begin{array}{l}\text { Meaningful } \\
\text { level }\end{array}$ & $\begin{array}{l}\text { Z Kolmogorov } \\
\text { Smirnov statistic }\end{array}$ & Research variables & Row \\
\hline Not normal & 0.0001 & 2.33 & Training of Customs Officers & 1 \\
\hline Not normal & 0.0001 & 2.325 & Getting heavy penalties from smugglers & 2 \\
\hline Not normal & 0.002 & 1.845 & $\begin{array}{l}\text { Compliance with government and customs } \\
\text { regulations }\end{array}$ & 3 \\
\hline Not normal & 0.0001 & 4.025 & Use of modern equipment and facilities & 4 \\
\hline Not normal & 0.001 & 1.924 & Rising fuel prices in the border regions & 5 \\
\hline Not normal & 0.0001 & 2.843 & Fuel retail in the border market & 6 \\
\hline Normal & 0.002 & 1.803 & Total & - \\
\hline
\end{tabular}

Result: If the variables are normal, parametric tests are recommended, otherwise non-parametric equivalent tests will be used. To determine the normality of the variables, the level of significance must be checked; the quality of the variables is recorded in the table.

\section{Testing hypotheses:}

Test of the first hypothesis: Customs staff training is effective in preventing the smuggling of fuel and oil products.

Considering that the effect of the training of customs personnel on the variable is not normal distribution, a nonparametric test of a sample sign will be used to test the hypothesis. Now if we suppose that:

M: The real median of the impact variable of the customs staff training in the studied society.

Therefore, the assumptions of the test will be as follows

$H_{0}$ : Customs personnel training is not effective in preventing the smuggling of fuel and oil products.

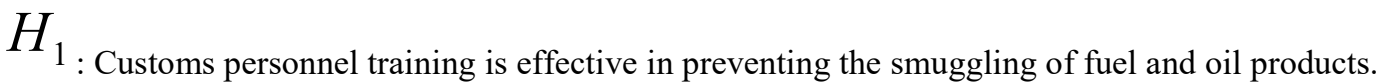

Considering that the effect of customs training staff variables is between 1 and 5 , therefore, we consider the values less than or equal to 3 as ineffective and more than 3 as effective. Therefore, we must consider Test the following assumptions:

$$
\left\{\begin{array}{l}
H_{0}: M \leq 3 \\
H_{1}: M>3
\end{array}\right.
$$

A test rule assumes zero in front of one as follows.

If only P-value $<0.05$ then let's suppose zero and accept a hypothesis.

Table 4-6: Results of the test of the variable sign of the first hypothesis

\begin{tabular}{|r|l|l|}
\hline Value & Statistics & Row \\
\hline 3.288 & Average & $\mathbf{1}$ \\
\hline 0.371 & Standard deviation & $\mathbf{2}$ \\
\hline 3.292 & Middle & $\mathbf{3}$ \\
\hline 11 & Less than middle & $\mathbf{1 - 4}$ \\
\hline 9 & Median number & $\mathbf{2 - 4}$ \\
\hline 80 & More than middle & $\mathbf{3 - 4}$ \\
\hline 0.0001 & meaningful level & $\mathbf{5}$ \\
\hline
\end{tabular}

As can be seen from the results of Table 4-6, the average of the effect of customs staff training on preventing the smuggling of fuel and oil products is 3.288 with a standard deviation of 0.371 and an average of 3.292 . The significance level of the test sign is equivalent to 0.0001 , therefore, we reject the assumption zero at the level of $\alpha=0.05$ the assumption zero and accept the opposite assumption, customs staff training is effective in preventing the smuggling of fuel and oil products. 
Test of the second hypothesis: Obtaining heavy crimes from smugglers is effective in preventing the smuggling of fuel and oil products.

Given that the impact of heavy smuggling is not a normal distribution in smugglers in preventing the smuggling of fuel and oil products, a non-parametric test of a sample sign will be used to test the hypothesis. Now if we suppose that:

M: The real median of the impact of taking heavy crimes from traffickers in preventing the smuggling of fuel and oil products in the investigated community.

Therefore, the assumptions of the test will be as follows:

$H_{0}$

: Obtaining heavy crimes against smugglers is not effective in preventing smuggling of fuel and oil products.

$H_{1}$

: Getting heavy crimes from smugglers is effective in preventing smuggling of fuel and oil products.

Table 4-7: Results of test of the variable sign of the second hypothesis

\begin{tabular}{|r|l|l|}
\hline Value & Statistics & Row \\
\hline 3.349 & Average & $\mathbf{1}$ \\
\hline 0.539 & Standard deviation & $\mathbf{2}$ \\
\hline 3.25 & Middle & $\mathbf{3}$ \\
\hline 17 & Less than middle & $\mathbf{1 - 4}$ \\
\hline 50 & Median number & $\mathbf{2 - 4}$ \\
\hline 33 & More than middle & $\mathbf{3 - 4}$ \\
\hline 0.0001 & meaningful level & $\mathbf{5}$ \\
\hline
\end{tabular}

As can be seen from the results of Table 4-7, the average impact of taking heavy crimes from smugglers in preventing smuggling of fuel and oil products is 34.33 with a standard deviation of 539 and a mean of 3.25 . The significance level of the test sign is equivalent to 0.0001 , so we reject the zero assumption at the level $\alpha=0.05$ of the assumption and accept the opposite, i.e., obtaining heavy crimes from smugglers in preventing the smuggling of fuel and oil products is effective.

Test of the third hypothesis: Governmental and Customs laws and regulations are effective in preventing the smuggling of fuel and oil products.

Given the fact that the variable of the effect of state and customs laws and regulations on preventing the smuggling of fuel and oil products does not have a normal distribution, a non-parametric test of a sample sign will be used to test the hypothesis. Now if we suppose that:

M: The real median of the impact of government and customs laws and regulations on preventing the smuggling of fuel and oil products in the community studied.

Therefore, the assumptions of the test will be as follows

$H_{0}$

: Government and customs regulations are not effective in preventing the smuggling of fuel and oil products.

$H_{1}$

: Government and Customs laws and regulations are effective in preventing the smuggling of fuel and oil products.

Table 4-8: Results of test of the variable sign of the third hypothesis

\begin{tabular}{|r|l|l|}
\hline Value & Statistics & Row \\
\hline 3.322 & Average & $\mathbf{1}$ \\
\hline 0.63 & Standard deviation & $\mathbf{2}$ \\
\hline 3.5 & Middle & $\mathbf{3}$ \\
\hline 21 & Less than middle & $\mathbf{1 - 4}$ \\
\hline 7 & Median number & $\mathbf{2 - 4}$ \\
\hline 72 & More than middle & $\mathbf{3 - 4}$ \\
\hline 0.0001 & Meaningful level & $\mathbf{5}$ \\
\hline
\end{tabular}

As can be seen from Table 4-8, the average of the impact of government and customs laws and regulations on preventing the smuggling of fuel and oil products is 3.322 with a standard deviation of 0.63 and a mean of 3.5 . The significance level of the test sign is equivalent to 0.0001 , so we reject the zero assumption at the level of $\alpha=0.05$ the assumption and accept the opposite, ie, the state and customs laws and regulations are effective in preventing the smuggling of fuel and oil products. 
Test of the forth hypothesis: The use of modern electronic equipment and equipment is effective in preventing the smuggling of fuel and oil products.

Given that the effect of the use of modern equipment and electronic equipment on preventing the smuggling of fuel and oil products is not normal distribution, a non-parametric test of a sample sign will be used to test the hypothesis. Now if we suppose that:

M: The real median of the impact of the use of modern equipment and electronic equipment in preventing the smuggling of fuel and oil products in the studied society.

Therefore, the assumptions of the test will be as follows

$H_{0}$

0 : The use of modern electronic equipment and equipment in preventing the smuggling of fuel and oil products is not effective.

$H_{1}$

: The use of modern electronic equipment and equipment is effective in preventing the smuggling of fuel and oil products.

Table 4-9: Test results variable test hypothesis fourth

\begin{tabular}{|r|l|l|}
\hline Value & Statistics & Row \\
\hline 3.292 & Average & $\mathbf{1}$ \\
\hline 0.59 & Standard deviation & $\mathbf{2}$ \\
\hline 3.25 & Middle & $\mathbf{3}$ \\
\hline 20 & Less than middle & $\mathbf{1 - 4}$ \\
\hline 18 & Median number & $\mathbf{2 - 4}$ \\
\hline 62 & More than middle & $\mathbf{3 - 4}$ \\
\hline 0.0001 & Meaningful level & $\mathbf{5}$ \\
\hline
\end{tabular}

As the results of Table 4-9 show, the average of the impact of the use of modern equipment and electronic equipment in preventing the smuggling of fuel and oil products is 29.23 with a standard deviation of 0.59 and a mean of 3.25. The significance level of the test sign is equal to 0.0001 , therefore, at the level of $\alpha=0.05$ the assumption zero, we reject the opposite, which means that the use of modern electronic equipment and equipment is effective in preventing the smuggling of fuel and oil products.

Test of the fifth hypothesis: Increased fuel prices in the border areas are effective in preventing the smuggling of fuel and oil products.

Given that the effect of increasing the price of fuel in border areas in preventing the smuggling of fuel and oil products does not have normal distribution, a non-parametric test of a sample sign will be used to test the hypothesis. Now if we suppose that:

M: The real median of the impact of rising fuel prices in the border areas in preventing the smuggling of fuel and petroleum products in the studied society.

Therefore, the assumptions of the test will be as follows

$H_{0}$ products.

$H_{1}$ products.

: The increase in fuel prices in the border areas is effective in preventing the smuggling of fuel and oil

Table 4-10: Results of the test of the variable sign of the fifth hypothesis

\begin{tabular}{|r|l|l|}
\hline Value & Statistics & Row \\
\hline 3.235 & Average & $\mathbf{1}$ \\
\hline 0.468 & Standard deviation & $\mathbf{2}$ \\
\hline 3.25 & Middle & $\mathbf{3}$ \\
\hline 23 & Less than middle & $\mathbf{1 - 4}$ \\
\hline 36 & Median number & $\mathbf{2 - 4}$ \\
\hline 41 & More than middle & $\mathbf{3 - 4}$ \\
\hline 0.0001 & Meaningful level & $\mathbf{5}$ \\
\hline
\end{tabular}

As the results of Table 4-10 show, the average of the effect of rising fuel prices in the border areas in preventing the smuggling of fuel and oil products is 3,353 with a standard deviation of 0.468 and an average of 3.25. The significance level of the test sign is equal to 0.0001 , therefore, we reject the zero assumption at the level of the assumption and accept the opposite, and that is, the increase in fuel prices in the border areas is effective in preventing the smuggling of fuel and oil products. 
Test of the Sixth hypothesis: Selling fuel at retail markets is effective in preventing the smuggling of fuel and oil products.

Due to the fact that the effect of the sale of fuel in retail markets in the form of retail sales in preventing the smuggling of fuel and oil products is not normal, a non-parametric test of a sample sign will be used to test the hypothesis. Now if we suppose that:

M: The real median of the impact of the sale of fuel in retail markets in the retail market in preventing the smuggling of fuel and oil products in the community studied.

Therefore, the assumptions of the test will be as follows

$H_{0}$

0 : Selling fuel at retail markets is not effective in preventing smuggling of fuel and oil products.

$H_{1}$

: Selling fuel at the border markets is effective in preventing the smuggling of fuel and oil products in retail.

Table 4-11: Results of the test of the variable sign of the sixth hypothesis

\begin{tabular}{|l|l|l|}
\hline Value & Statistics & Row \\
\hline 3.272 & Average & $\mathbf{1}$ \\
\hline 0.829 & Standard deviation & $\mathbf{2}$ \\
\hline 3.25 & Middle & $\mathbf{3}$ \\
\hline 41 & Less than middle & $\mathbf{1 - 4}$ \\
\hline 20 & Median number & $\mathbf{2 - 4}$ \\
\hline 39 & More than middle & $\mathbf{3 - 4}$ \\
\hline 0.0001 & meaningful level & $\mathbf{5}$ \\
\hline
\end{tabular}

As can be seen from the results of Table 4-35, the average of the impact of fuel sales on the border markets in retail to prevent the smuggling of fuel and oil products was 3.272 with a standard deviation of 0.829 and a mean of 3.25. The significance level of the test sign is equivalent to 0.0001 , therefore, we reject the zero assumption at the level of $\alpha=0.05$ the assumption and accept the opposite, that is, selling fuel in the marketplaces in the retail market is effective in preventing the smuggling of fuel and oil products.

\section{Conclusion}

Considering that the main issue of this study is the effect of deterrent factors on the smuggling of fuel and oil products in Iran's customs (Case study of Birjand Mahirood Frontier Customs), the following are the results of this research:

The result of the first hypothesis:

Customs personnel training is effective in preventing the smuggling of fuel and oil products.

The result of the second hypothesis:

Obtaining heavy crimes from smugglers is effective in preventing the smuggling of fuel and oil products.

The result of the third hypothesis:

Governmental and custom laws and regulations are effective in preventing the smuggling of fuel and oil products.

The result of the fourth hypothesis:

The use of modern electronic equipment and equipment is effective in preventing the smuggling of fuel and oil products.

The result of the fifth hypothesis:

An increase in fuel prices in the border areas is effective in preventing the smuggling of fuel and oil products.

The result of the sixth hypothesis:

Selling fuel at retail markets is effective in preventing the smuggling of fuel and oil products.

The basic point is that the research process never ends. The findings are always the findings of any experimental research, and there is the awareness that further research may prove that the results have been incorrect (Irannejad, p. 24: 1382)

\section{References}

$>$ Ansari, Mohammad Reza (1373) Smuggling and its causes, Customs Publication Chapter III

$>$ Hashemi, Parvin (2003) Review the views of customs managers and customs on how to reduce smuggling of goods, master's thesis.

$>$ Seyfi, Alireza (1390) Customs in Iran, Iranian Customs Publications

$>$ Arabi, Seyyed Mohammad (2001) Strategies, Plans and Solutions for Implementing Good Occupational Safety in Administrative System, Journal of Management Studies. Sun: 30-29.

$>$ Aghababaei, Razieh, Hoveyda, Reza, Siyadat, Ali and Rahimi Hamid. (2011), Analysis of Strategic Strategies for Smuggling Reduction, Third Year, No. 5. 
$>$ Alwani, Seyyed Mahdi (2000), Public Administration, 10th edition, Tehran, Iran.

> Amrullahi Boyuki, Nahid (2001) An Examination of Barriers to Efficient Human Resources, Case Study: Iran Khodro Sales Organization, Master's Thesis, Tarbiat Modares University.

$>$ Bazargan, Abbas, Sarmad, Zohreh and Hejazi, Elaheh (2003) Research Methods in Behavioral Sciences, Seventh Edition, Informative Publishing.

$>$ Blanchard et al. (1999), Organizational Behavior Management, Translator: Ali Pashband, Tehran, Amir Kabir Publishing.

$>$ Blanchard, Ken (2000) 3 Key to Power Generation, Translator: Fazl A. Amini, Faraz Publishing, First Printing, winter.

$>$ Jahed Tabrizi, Amir (2008) Employee Security, Successful Organizations, Message Iran Khodro, No. 30, Third Year, Farvardin 2008.

$>$ Jazani, Nasrin (1999) Human Resource Management, Tehran, Ney Publications.

$>$ Bell, S. T. 2007. Deep-level composition variables as predictors of team performance: A meta-analysis. Journal of Applied Psychology, 92: 595-613.

$>$ Campbell Constance R \& Martinko Mark J. (1998) "An Integrative Attributional Perpective of Empowerment and Learned Helpessnes: A Multimethod Field Study”, Journal of Management, Vol.24, No.2.

$>$ Cohen, S. G., Ledford, G. E., \& Spreitzer, G. M. (1996) A predictive model of self-managing work team effectiveness. Human Relations, 49: 643-676.

$>$ Congerjay a \& Kanungo Rabindra N. (1998) "The Empowerment Process: Integrating Theory and Practice: Academy of management Review, Vol.13, No.3.

$>$ Frayne, C. A., \& Latham, G. P (1987). Application of social-learning theory to employee selfmanagement of attendance. Journal of Applied Psychology, 72: 387-392.

$>$ Frese, M., \& Frey, D. (2001) Personal initiative PI: The theoretical concept and empirical findings. Research in Organizational Behavior, 23: 133-187.

$>$ Hardy Cynthia \& Leiba - Osullivan Sharon, (1998) "The Power Behind Empowerment: Implication for Research and Practice”, Human Relations, Vol.51, No.4. 